\title{
Assessing the Demographic Consequences of the Covid-19 Pandemic
}

Emily Klancher Merchant

Follow this and additional works at: https://knowledgecommons.popcouncil.org/series_pdr_essays-covid How does access to this work benefit you? Let us know!

\section{Recommended Citation}

Merchant, Emily Klancher. "Assessing the Demographic Consequences of the Covid-19 Pandemic." In Covid-19 and the Global Demographic Research Agenda, edited by Landis MacKellar and Rachel Friedman, 37-41. New York: Population Council, 2021. 


\title{
Assessing the Demographic Consequences of the Covid-19 Pandemic
}

\author{
EMILY KLANCHER MERCHANT
}

DEMOGRAPHERS AND OTHER SOCIAL SCIENTISTS have long recognized that socalled natural disasters are always also social and political. While extreme weather events, earthquakes, famines, and pandemics may originate in nature, their effects are always structured by existing social inequities and by political responses. In the Anthropocene-our current geological epoch, in which biogeochemical change is primarily driven by human activities-it has become clear that even the origins of such disasters are not entirely natural. Natural disasters are typically localized in space, usually within countries, foreclosing the possibility of comparative analysis. As a global pandemic, however, the Covid-19 event affords demographers an unusual research opportunity. As demographers investigate the demographic consequences of the pandemic in the regions with which they are most familiar, they should also collaborate on comparative analysis to determine how social inequities and political responses in various parts of the world mediated between a global disease and its local demographic effects.

The Covid-19 pandemic has by now had an unmistakable impact on each of the core demographic processes-mortality, fertility, and migrationin all parts of the world. It has also affected the collection of demographic data. This essay describes some of the demographic consequences in the United States in order to point to opportunities for comparison with other parts of the world. To investigate these consequences, demographers will need data and methods with which to measure the short- and long-term effects of the Covid-19 pandemic on fertility, mortality, and migration, taking into account global disease processes, local social structures, and political responses at the level of public health institutions. (In many countries, this is the national level, but, in the United States, it has typically been the state or county level.) Such comparative research will not only help us better understand why Covid-19 had the demographic consequences it had (and will continue to have) in each part of the world, but may also point to ways we can make societies

Emily Klancher Merchant, Science and Technology Studies, University of California Davis.

POPULATION AND DEVELOPMENT REVIEW I ESSAYS (FEBRUARY 2021) 
around the world more resilient in the face of future disasters that may not be individually predictable, but are sure to come in one form or another, particularly as the pace of climate change increases.

\section{Mortality}

Perhaps the most obvious demographic consequence of the Covid-19 pandemic has been an increase in mortality, both from the disease caused by the SARS-COV2 virus and from the secondary effects of the virus on health systems and economies. According to the Johns Hopkins University Coronavirus Resource Center, more than 1.8 million people worldwide have died from Covid-19 at the time of this writing, with over 350,000 deaths-approximately 19 percent of the total-occurring in the United States. While the early rhetoric surrounding Covid-19 maintained that the disease does not discriminate, it quickly became clear that not everyone is equally susceptible. People who are unable to isolate are at greater risk of contracting the disease, while those who are older or carry a heavier burden of preexisting conditions and comorbidities are less likely to survive it. In the United States, these categories intersect with one another and with the categories that structure social inequality, in this case race and socioeconomic status. Poor and nonwhite Americans are less likely to be able to isolate-due to service-sector and factory jobs, jobs that do not offer paid (or sometimes even unpaid) sick time, and household crowding - and are more likely to carry comorbidities as a result of living in food deserts, the inequitable siting of environmental hazards, and stark inequalities in access to health care. In other countries, different histories of social inequality will likely structure mortality in different ways. Also critical is the public health response to the pandemic, which was abrupt and highly effective in many parts of Asia (including Australia and New Zealand), somewhat less so in Europe, and truly deplorable in the United States and some parts of Latin America. Comparative research on the short- and long-term mortality consequences of Covid-19 will need to tease the effects of the disease itself apart from the underlying social conditions that made some people more susceptible to it and from the political and public health response.

\section{Fertility}

In contrast to the mortality consequences of Covid-19, which became apparent very early on and have been diligently tracked by a number of agencies, it may take several years to fully understand and account for the fertility consequences. These studies, too, will need to examine the results of the disease itself, such as the potential effects of Covid-19 on sperm production; underlying social inequities, such as existing risks of maternal and perinatal 
mortality, which may have been exacerbated by the pandemic; and policy responses that may shape future childbearing decisions through the distribution of the burden of childcare. In the United States, the immediate effects of Covid-19 on fertility operated through those who were pregnant when the pandemic began and those who were in the process of trying to conceive with the help of various assisted reproductive technologies (ART). Among those who were pregnant when the pandemic began, the same women who already face higher risks of maternal and perinatal mortality-poor women and especially black women and Latinas-also faced a higher risk of contracting Covid-19. Those who were trying to conceive using ART had to pause this process while health systems retooled to focus on treating Covid-19. As the pandemic wore on, however, fertility clinics reopened, and many people renewed their efforts to conceive.

In the long run, policy responses to the pandemic will also affect fertility through the future childbearing decisions of individuals and couples. In the United States, the pandemic demonstrated that, even at the best of times, most families get by only through a delicate balancing act, piecing together the inadequate and largely unregulated childcare resources that are available to those who can afford them. When the pandemic shut down schools and day care centers in March, it was largely mothers who put their careers on hold to take care of young children and to help older children navigate their classes on Zoom. This is not a natural response to the pandemic, but rather one overdetermined by a long history of gender discrimination in the labor force and an absence of policies to support working mothers and dual-career families. Indeed, the same factors that have kept fertility lower in countries like Italy and Japan, where mothers are primarily responsible for childcare, than in countries like Sweden, where there is more public support for dualcareer families, will also determine the long-term fertility consequences of Covid-19.

\section{Migration}

The migration consequences of the Covid-19 pandemic will also need to be evaluated in both the short- and long-term. When it became clear that the SARS-COV2 virus was going to cause a pandemic, countries around the world began to limit travel and close borders. As a result, many international sojourners returned to their countries of origin, while others decided to remain abroad for the duration. An unexpected consequence was that, as workers abroad were prevented from returning home due to travel restrictions, the migrant smuggling business developed a sideline of smuggling people back home. As universities scrambled to shift classes online, many also closed their dormitories, sending students home to various parts of the world. These relocations are likely to be relatively short-lived. Most universities and college 
students are anxiously awaiting a return to campus life, and restrictions on travel will undoubtedly ease when a vaccine or effective treatments become available. The increase in remote work, however, may have a longer-term impact on migration. Now that it has become apparent that many jobs can be done remotely, some large employers have begun to reevaluate their workfrom-home or telecommuting policies, and smaller employers are likely to follow suit. An increase in opportunities to work remotely will also afford some people-those with jobs that can be done remotely-a broader set of choices over where to live that could dramatically reshape social geographies. An impressive number of countries, ranging from Antigua to Georgia, are offering one-year renewable remote work visas to "digital nomads" who can demonstrate income and health insurance and afford to pay a fairly modest fee. Demographers will need to investigate the determinants of migration when some people are no longer geographically bound by their jobs, and should examine how the extreme mobility of some workers-typically those with jobs that pay more and offer better benefits-affects the fortunes of immobile workers, such as those in service industries that rely on proximity to their clientele. As with mortality and fertility, the migration consequences of the Covid-19 pandemic and the shift to remote work will be shaped primarily by underlying social structures and public policies.

\section{Demographic Data}

In addition to its effects on mortality, fertility, and migration rates and patterns, the Covid-19 pandemic has also had consequences for the collection of demographic data. This has been most apparent in the United States, where the in-person enumeration of households that did not return their 2020 Census form by mail or respond online was first delayed by the pandemic and then curtailed prematurely by the Trump administration, likely leading to an unnecessarily high rate of undercounting. Under ordinary circumstances, it is relatively straightforward for demographers to determine who was missed by a census. However, the enormous demographic upheavals generated by the Covid-19 pandemic will likely make this task more difficult. One particular challenge stems from the fact that many of the people who are most vulnerable to undercounting - the poor and non-White, as well as non-English-speakers - are also particularly vulnerable to Covid-19 mortality. Another stems from the fact that most U.S. universities closed in March, scattering students across the country and the world right before the Census. The American media has paid particular attention to the 2020 U.S. Census because of the controversies that had already surrounded it-most notably the citizenship question-and because of the political consequences of undercounting. However, the United States is not alone in the impact the Covid-19 pandemic has had on its census. Since 1950, the United Nations has 
encouraged all countries of the world to take censuses in or near years ending in zero, so many countries have had to manage enumeration in the midst of the pandemic. While a few countries—such as Mexico and Mongoliacompleted their data collection early in the year, most have had to suspend or delay enumeration, or substitute data from population registers or other administrative records. The pandemic will, therefore, have a larger effect on demographic data collection in countries that lack adequate administrative records and communication infrastructures that would facilitate enumeration by mail, telephone, or Internet rather than in person.

As a global pandemic unfolding simultaneously across the world, the Covid-19 episode affords unique opportunities for comparative research on all of the basic demographic processes. Such research may be able to determine the specific contributions of the disease itself, underlying social inequities, and policy responses to changes in mortality, fertility, migration, and censustaking. Understanding these natural, social, and political factors will be critical to evaluating vulnerability to future natural (and not-so-natural) disasters, and to promoting resilience. 